\title{
Seismic activity of major hidden faults in the Priamurye region
}

\author{
Svetlana Tusikova*, Tatyana Merkulova and Gulshat Gil'manova \\ Yu.A. Kosygin Institute of Tectonics and Geophysics, Far East Branch, Russian Academy of \\ Sciences, ul. Kim Yu Cheha 65, Khabarovsk, 680000 Russia
}

\begin{abstract}
Based on the data of the relief analysis and the geophysical fields, major submeridional and NW-trending hidden faults are detected in the Priamurye region. The seismic energy calculations are performed for the instrumental observation period given the historical events. The faults showing the highest seismic activity are revealed. The seismic energy released by hidden faults is commensurable with a similar value obtained for the seismoactive faults detected from the geological data. Key works: geophysical anomalles, hidden faults, seismic energy, seismic activity, Priamurye
\end{abstract}

\section{Introduction}

The issues related to the construction of geodynamic models dealing with the formation and detection of mineral deposits of various types lead to the detection of hidden faults. Moreover, studying of these structures acquires special significance for the seismic hazard assessment in the region and the detection of the seismoactive zones. Under hidden faults we mean the faults that are not exposed at the surface but are manifested in the deep crustal layers. Such fault structures may appear to be either young faults originated at the modern stage, or old ones that were tectonically inactive for a long time. According to the modern concepts, major faults appear to be 3D bodies having a dynamic influence zone. A great experience in detecting and studying hidden faults has been accumulated by now [1]. To detect hidden faults from indirect indications, their specific features such as fracturing, fluid saturation, the presence of linear magmatic formations, controlling of blocks of various ranks, the sedimentary cover structures and others are taken into consideration. These indications may be displayed in lineaments of the relief and areas of their increased density, narrow linear magnetic and gravity anomalies due to magmatic rock intrusion and areas where specific features of the structure or intensity of these anomalies have undergone changes, the abnormal Vp/Vs ratio values, etc. Hidden faults are frequently discovered due to lack of the relationship between large earthquakes and the faults identified from the geological data and their intersection areas or the arrangement of seismoactive zones and seismic energy characteristics in the opposite direction with respect to that revealed at the fault surface. The hidden faults which do not correlate, or correlate in separate segments only with the faults discriminated at the surface from the geological data, have been

\footnotetext{
* Основной автор: svetabon@list.ru
} 
distinguished. The sketch-maps of fault tectonics of the Priamurye region show predominance of the NE-trending faults which is linked to high activity of the Tan-Lu Fault System during the Mesozoic-Cenozoic [2] (Fig. 1). However, the analysis of seismicity in the region has shown that the seismoactive zones and seismolineaments are often localized submeridionally or in the northwestern direction $[3,4,5]$.

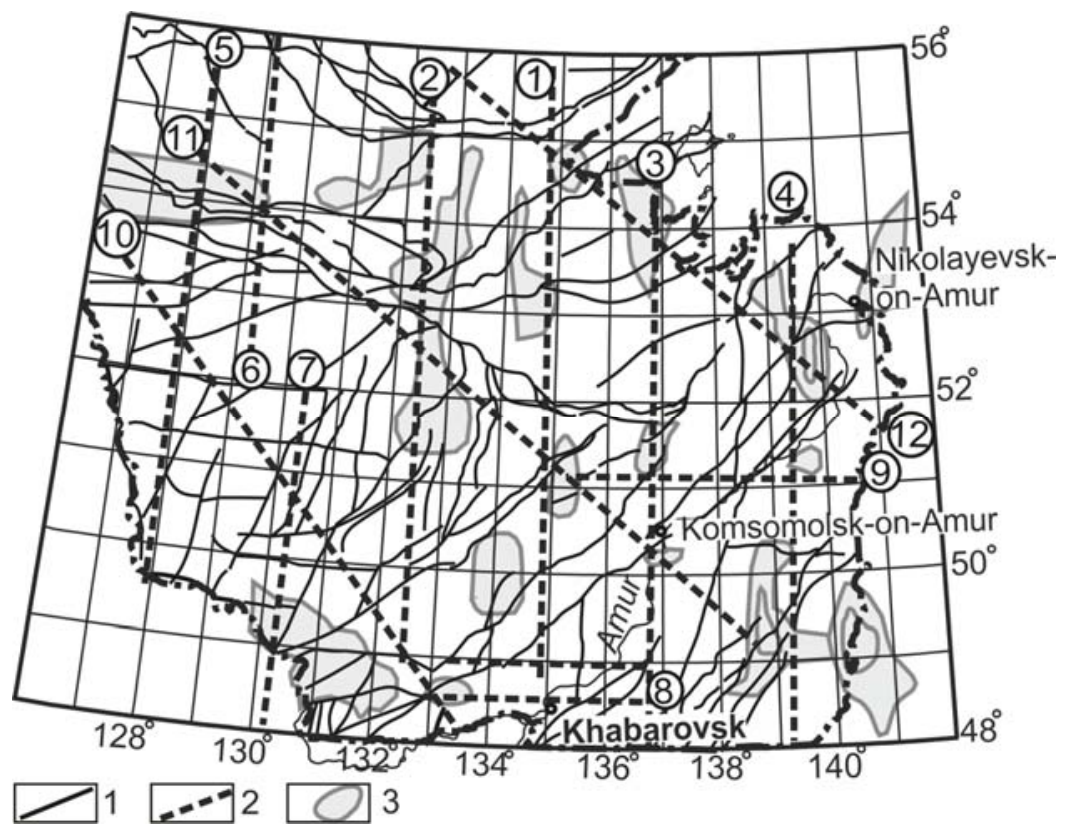

Fig. 1. A sketch-map of fault tectonics and zones of the maximum seismic energy release in the Priamurye region. 1 - regional faults after [2]; 2 - "hidden" faults; 3 - zones of the maximum seismic energy release after [3].

Our earlier studies allowed us to distinguish a series of hidden faults of various ranks that are dominantly submerional or NW-trending and, rarely, sublatitudinal. In connection with this, we needed to summarize the geological-geophysical data in order to detect and trace the major faults, and to estimate their seismic activity.

\section{Investigation technique}

To detect hidden faults, we performed the relief analysis based on the digital elevation models (DEMs) SRTM-03 (Shuttle Radar Topography Mission Survey). The statistical analysis was further performed applying the program technique LESSA (Lineament Extraction and Stripe Statistical Analysis). As a result of the relief analysis, the following maps have been compiled: the map of the dominant extension lines of rose charts, the maps of the overall density of all lineaments of various directions, and the maps of linear elements showing different degrees of manifestation. To study the fault indications in the geophysical fields we used the gravity and magnetic field maps, scales of 1: 1000000 , which were processed using the COSCAD 3D computer program developed by Petrov. The observed gravity and magnetic data were decomposed into the regional and local components, after that the anomaly axes tracing procedure was performed. The data on the abnormal $\mathrm{Vp} / \mathrm{Vs}$ ratio values and the schemes of the seismic energy and seismic activity were also involved in the detection of hidden faults [3, 4, and 6]. Significantly long hidden faults identified from a number of indications are related to major faults. To estimate 
seismicity we used the data on the earthquakes with magnitudes larger than 2.0 including the historical events recorded during the 1960-2015 instrumental observation period which were taken from the catalog created at the Institute of Tectonics and Geophysics of the Far East Branch of the Russian Academy of Sciences (ITiG FEB RAS). We calculated the cumulative seismic energy released in the dynamic influence zone $(50 \mathrm{~km})$.

\section{Results and discussion}

In the region, the submeridional and sublatitudinal faults are often related to old ones that are manifested in the deep crustal and mantle layers to a larger extent. The faults controlling a large regional negative anomaly from east and west, as well as those running through its central part are related to the major submeridional faults in the first place (Fig. 2).

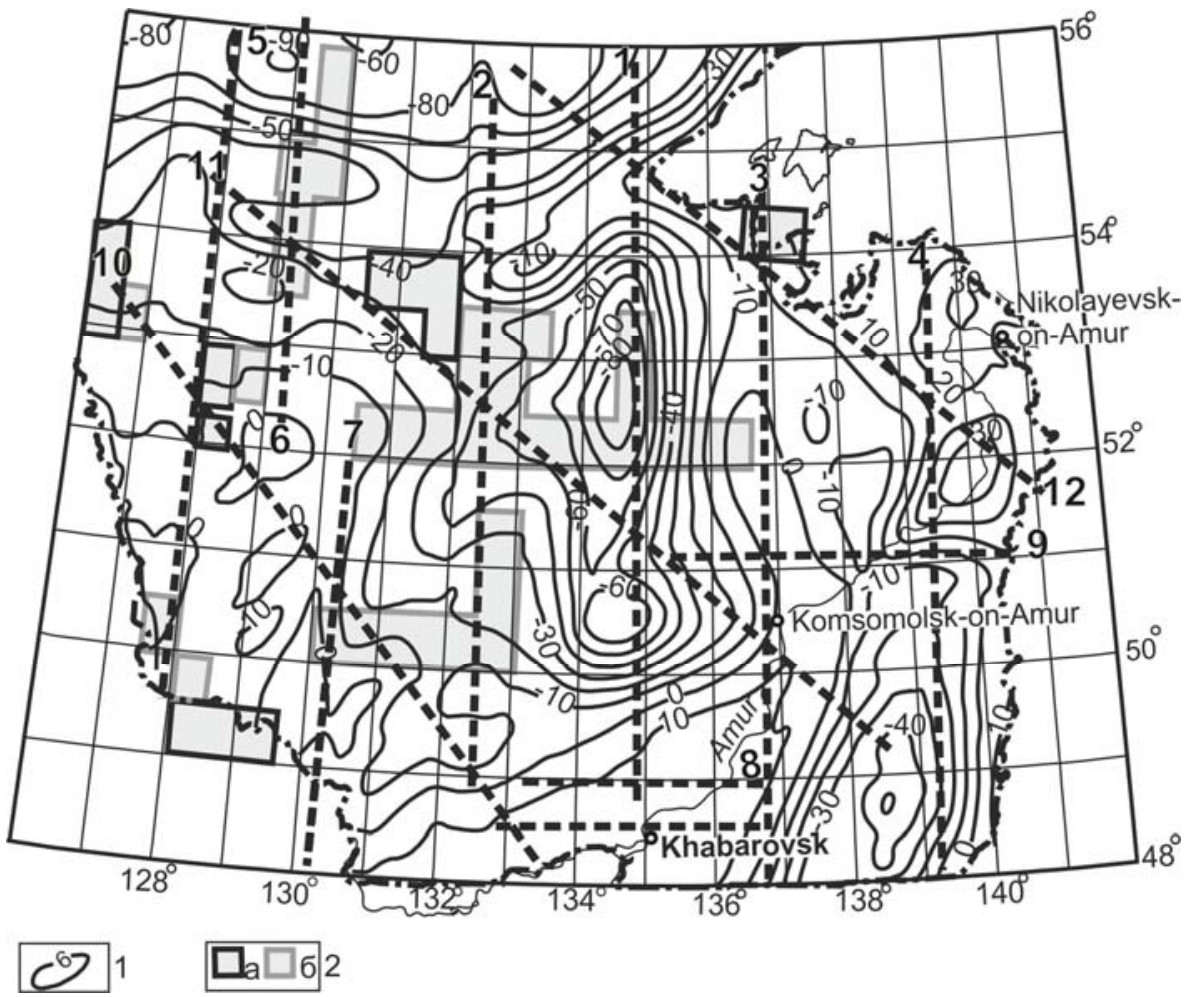

Fig. 2. Indications showing hidden faults manifested in the regional gravity anomalies and revealed from the abnormal $\mathrm{Vp} / \mathrm{Vs}$ ratio values.

1 - isolines showing the regional gravity field components; 2 - the abnormal $\mathrm{Vp} / \mathrm{Vs}$ ratio zones after [6]: a - high, b - low. For other explanations see Fig. 1.

Fault zone 1 is affirmed in the central part by a meridionally extended area of the abnormally low $\mathrm{Vp} / \mathrm{Vs}$ ratio values, while in the northern part a similar orientation of the dominant extension lines is noted. The fault zone exhibits an increased density of lineaments of the relief of various directions over an entire length, which is indirect evidence of the increased fracturing zone (Fig. 3). From the western side of the regional anomaly, Fault zone 2 correlates with the seismically active zone of similar orientation, coincidental with the abnormally low Vp/Vs ratio values. Major Fault 3 is evidenced from a series of submeridionally extended sedimentary depressions of the Lower Amur Basin and 
a similar orientation of the linear magnetic anomalies typical of the extension regime from the east. The Vyunsky Fault is detected from the geological data in the easternmost part, which may be continued for a large distance in the southern direction in accordance with persistent predominance of the submeridional extension lines (Fault 4). In this area, we observe the extension lines of the regional gravity field component and localization of the submeridionally oriented anomaly of the seismic energy. In the western part of the region, three major submeridional faults have been distinguished. Major Fault 5 is detected from submeridionally arranged local gravity anomalies, which show consistency with the direction of the extension lines in the southern part. Fault 6 is determined from the anomaly of the seismic activity and the abnormal Vp/Vs ratio values. Fault zone 7 is identifiable from the zone of the abnormally high seismic activity and breaks in the extension lines.

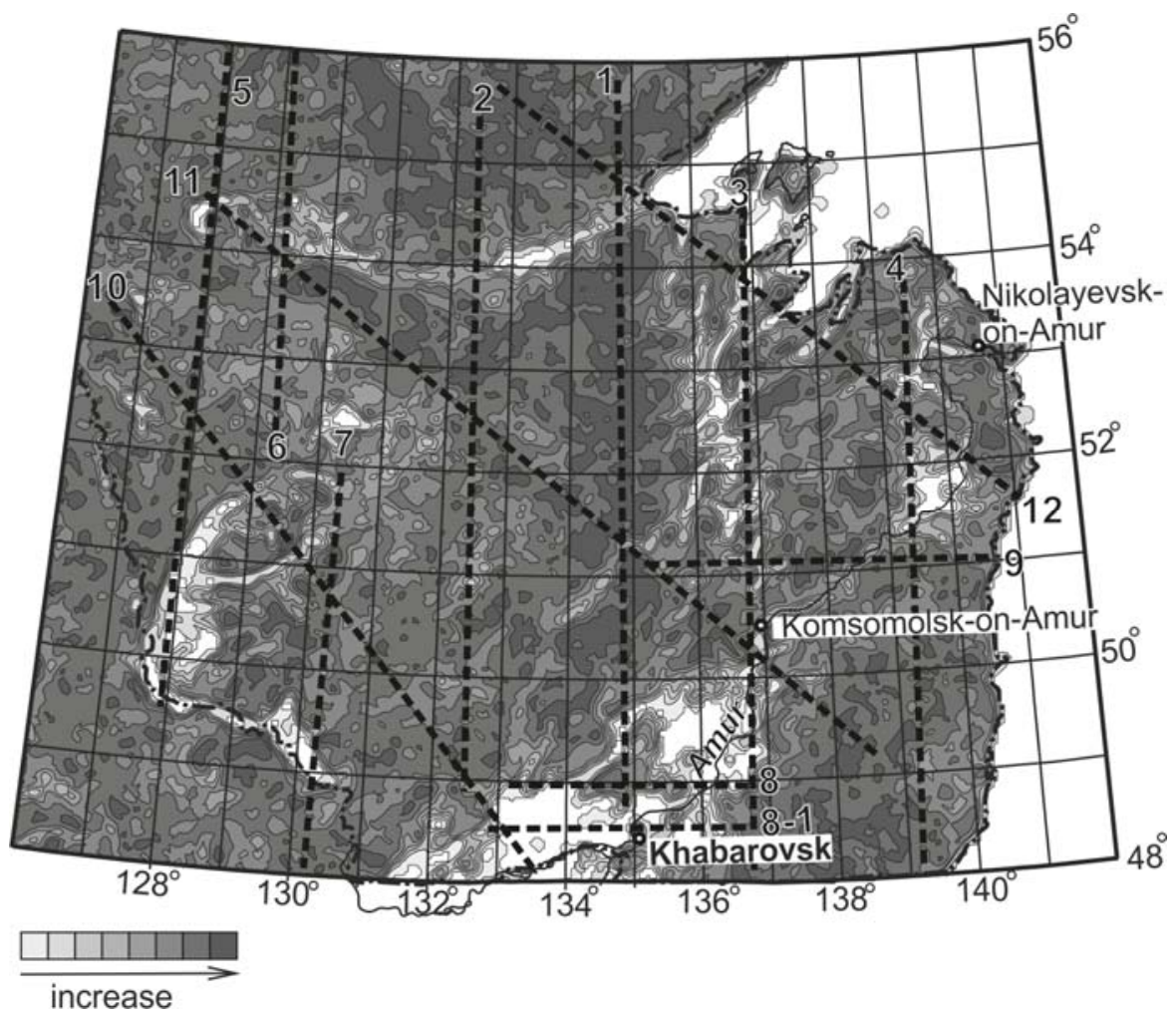

Fig. 3. The density of lineaments of various directions. For other explanations see Fig. 1.

Three sublatitudinal faults can be emphasized that are the continuation of the regional faults detected from the geological data. Faults 8 and 8-1 are located on the continuation of the Bira and Pompeevsky faults and further border a series of the northeastern sublatitudinal grabens of the Middle Amur Basin. They are similarly manifested in the local gravity anomalies. Fault 9 is found to be located in the eastern part of the region, but it may be assumed to occur on the continuation of the Svobodnensky Fault [2]. The fault is manifested as a sublatitudinal structure that controls the major gravity anomalies in the easternmost part of the region. Three hidden NW-trending faults distinguished on the scheme of lineaments can be related to major faults. Fault 10 constrains the local gravity anomalies of the northeastern orientation displacing them in the southern part. It is similarly manifested in the anomalies of the overall density of lineaments, that is, it controls the distribution of small sublatitudinally oriented anomalies of the increased density of lineaments of the northeastern direction. The longest Fault 11 is identified in the central 
part of the region and is traced by the anomalies of the increased density of lineaments, and the magnetic anomalies over an entire length. The fault controls variations in the intensity of the magnetic field starting from the positive anomalies from the southwestern part up to weakly negative anomalies toward the northeast. Here a change in the structural plan of the first-order local gravity anomalies is notable: the anomalies are northeasterly arranged from the northwest, whereas toward the northeast we observe changes in the anomaly shape up to isometric or the anomalies have a complicated shape. Fault 12 is manifested in a series of small fractures detected from the geological data, the arrangement of earthquakes and NWoriented magnetic anomalies. Hidden faults numbered 1, 3, 7, 9, 11, and 12 exhibit the highest seismic energy released during the instrumental observation period (tab).

Table 1. Seismic energy of major hidden faults in the Priamirye region

\begin{tabular}{|l|l|l|}
\hline Fault No. & $\begin{array}{l}\text { Seismic energy } \\
\text { (including historical } \\
\text { earthquakes), gigajoule }\end{array}$ & $\begin{array}{l}\text { Seismic energy } \\
(1960-2015), \\
\text { gigajoule }\end{array}$ \\
\hline 1 & $\mathbf{4 7 7 5 7}$ & $\mathbf{4 7 4 5 7}$ \\
\hline 2 & 19330 & 18797 \\
\hline 3 & $\mathbf{3 0 1 5 7}$ & $\mathbf{2 9 4 4 8}$ \\
\hline 4 & $\mathbf{8 8 2 7 4}$ & 9203 \\
\hline 5 & 9065 & 8939 \\
\hline 6 & 8915 & 8852 \\
\hline 7 & $\mathbf{2 8 4 8 6}$ & $\mathbf{2 5 4 4 1}$ \\
\hline 8 & 9719 & 3731 \\
\hline 9 & $\mathbf{4 7 8 0 0}$ & $\mathbf{2 0 7 3 1}$ \\
\hline 10 & 12506 & 6529 \\
\hline 11 & $\mathbf{4 0 2 8 7}$ & $\mathbf{3 9 4 5 4}$ \\
\hline 12 & $\mathbf{1 2 1 3 1 0}$ & $\mathbf{5 7 5 8 5}$ \\
\hline
\end{tabular}

The seismic energy value released at Fault 4 is insufficient but given the historical events it attains the higher value, which should be taken into consideration for the seismic hazard assessment. The seismic energy values obtained for the hidden faults are commensurable with similar estimates for the seismically active faults detected from the geological data. Given the historical events occurred on the NE-trending Yitong-Yilan Fault System the seismic energy reaches 74855 gigajoules in the Priamurye region whereas at the Stanovoy it is 122620 gigajoules, respectively. The most seismically active hidden faults 1,11 , and 12 are traced by the anomalies of the increased density of lineaments over the entire extent, which are indirect evidence of fracturing. This indication can be used for estimation of the seismic activity of smaller faults.

\section{Conclusions}

1. Based on the data of the comprehensive relief analysis and the geophysical fields, the major NW, submeridional, and sublatitudinal faults have been detected.

2. The released seismic energy values obtained for the hidden faults are commensurable with similar values for the faults detected at the surface from the geological data.

3. The major seismically active hidden faults are clearly manifested in the anomalies of the lineament density, which indicates a high degree of fracturing. 
This study was supported by the Russian Science Foundation (project no. 16-17-00015).

\section{References}

1. K. F. Tyapkin, T. T. Kivelyuk, Study of Fault Structures by Geological-Geophysical Methods (Nedra, Moscow, 1982)

2. V. Yu. Zabrodin, O. V. Rybas, G. Z. Gil'manova, Fault Tectonics of Continental Russian Far East (Dalnauka, Vladivostok, 2015)

3. A. N. Didenko, V. S. Zakharov, G. Z. Gil'manova, T. V. Merkulova, M. V. Arkhipov, J. Pac. Geol. 11 (2), 123-133 (2017)

4. D. A. Safonov, T. V. Nagornykh, and N. S. Kovalenko. Seismicity of the Amur and Primorye Regions (IMGiG DVO RAN, Yuzhno-Sakhalinsk, 2019)

5. Geodynamics, magmatism and metallogeny of the Russian East, edited by A. I. Khanchuk, 1, (Dalnauka, Vladivostok, 2006)

6. T. V. Nagornykh, L. I. Poplavskaya, Seismological Observations at the USSR Far East (Nauka, Moscow, 92-105, 1989)

7. A. Zlatopolsky, Computers\&Geosciences, 23 (1), 45-62 (1997) 